\title{
Prevalence of illicit and prescribed neuropsychiatric drugs in three communities in Kentucky using wastewater-based epidemiology and Monte Carlo simulation for the estimation of associated uncertainties
}

\author{
Tara Croft \\ Murray State University, tcroft@murraystate.edu \\ Rhiannon Huffines \\ rhuffines@murraystate.edu \\ Manoj Pathak \\ Murray State University, mpathak@murraystate.edu \\ Bikram Subedi \\ Murray State University, bsubedi@murraystate.edu
}

Follow this and additional works at: https://digitalcommons.murraystate.edu/faculty

\footnotetext{
Recommended Citation

Croft, Tara; Huffines, Rhiannon; Pathak, Manoj; and Subedi, Bikram, "Prevalence of illicit and prescribed neuropsychiatric drugs in three communities in Kentucky using wastewater-based epidemiology and Monte Carlo simulation for the estimation of associated uncertainties" (2020). Faculty \& Staff Research and Creative Activity. 91.

https://digitalcommons.murraystate.edu/faculty/91
}

This Journal Article is brought to you for free and open access by Murray State's Digital Commons. It has been accepted for inclusion in Faculty \& Staff Research and Creative Activity by an authorized administrator of Murray State's Digital Commons. For more information, please contact msu.digitalcommons@murraystate.edu. 


\title{
Prevalence of illicit and prescribed neuropsychiatric drugs in three communities in Kentucky using wastewater-based epidemiology and Monte Carlo simulation for the estimation of associated uncertainties
}

\author{
Tara L. Croft ${ }^{\mathrm{a}}$, Rhiannon A. Huffines ${ }^{\mathrm{a}}$, Manoj Pathak ${ }^{\mathrm{b}}$, Bikram Subedi ${ }^{\mathrm{a}}{ }_{*}$ \\ ${ }^{a}$ Department of Chemistry, Murray State University, Murray, KY, United States \\ ${ }^{\mathrm{b}}$ Department of Mathematics and Statistics, Murray State University, Murray, KY, United States
}

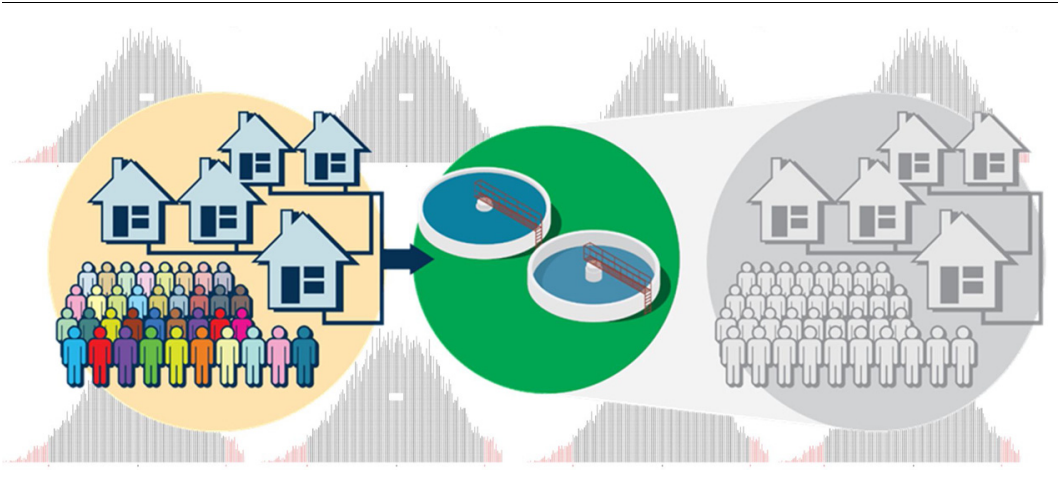

\section{A R T I C L E I N F O}

Editor: Xiaohong Guan

Keywords:

Illicit drugs

Wastewater-based epidemiology

Monte Carlo simulation

Ammoniacal-nitrogen-based-population

Drug consumption

\begin{abstract}
A B S T R A C T
A cost-effective alternative approach capable of determining the prevalence of substance use in communities can complement the existing efforts of combating drug abuse and addiction. In this study, the prevalence of 10 illicit and 19 prescribed psychoactive drugs of potential abuse was determined utilizing wastewater-based epidemiology, and compared in two adjoined urban communities and a rural community. This is the first application of the Monte Carlo simulation method to account multiple uncertainties and propagation of errors associated with the individual parameter of wastewater based epidemiological estimations in the U.S. A significantly higher prevalence of cocaine [3830 (mean difference, MD: 2960) mg/d/1000 people] was found in the central business district while the per-capita consumption rates of amphetamine [738 (MD: 338) mg/d/1000 people] and methamphetamine [1660 (MD: 629) mg/d/1000 people] were higher in a rural community. Among narcotics, the per-capita consumption rate of fentanyl and morphine was significantly higher in urban communities while codeine, hydrocodone, hydromorphone, and buprenorphine were dominant in a rural community. The significantly higher prevalence of buprenorphine ( $20-30$ folds), oxycodone ( $\sim 2-3$ folds), and alprazolam ( $2-3$ folds) determined in these communities compared to the conventional estimates based on the electronically reported prescriptions and drug-related inpatient hospitalizations suggest the abuse of these drugs.
\end{abstract}

\footnotetext{
* Corresponding author at: Department of Chemistry, Murray State University, 1201 Jesse D. Jones Hall, Murray, KY 42071, United States.

E-mail address: bsubedi@murraystate.edu (B. Subedi).
} 


\section{Introduction}

The prevalence of substance uses and addiction is growing as a global threat to social and economic well-being (United Nation Office on Drugs and Crime, 2018). In the U.S., the ongoing opioid epidemic was declared in 2017 as a national public health emergency, while other drugs of abuse remain prevalent (U. S. Department of Health and Human Services, 2019). For the first time in half a century, the life expectancy in the U.S. has declined in 2015 and 2016 with a key factor being a rise in drug-related deaths. Therefore, the timely, cost-effective, and comprehensive measure of the prevalence of substance use has never been more imperative before.

Wastewater-based epidemiology (WBE) is a fast-growing approach for the estimation of consumption of a chemical substance in the community as complementary to the conventional survey-based approaches (Foppe et al., 2018; O'Brien et al., 2019). WBE has been exploited to estimate the consumption statistics of the illicit drugs (European Monitoring Center for Drugs and Drug Addiction (EMCDDA), 2019; Australian Criminal Intelligence Commission (ACIC), 2019; Subedi and Kannan, 2014; Burgard et al., 2019), potentially abused prescribed drugs (Subedi et al., 2015; Skees et al., 2018), as well as evaluate the human exposure to the classic persistent pollutants such as pesticides (Rousis et al., 2017), emerging pollutants such as flame retardants (Been et al., 2018) and phthalates (González-Mariño et al., 2017; Du et al., 2018), and several other public health biomarkers such as diet (Venkatesan et al., 2019), pathogenic bacteria (Fernandez-Cassi et al., 2018), and virus (Prado et al., 2012). In WBE, the trace level of drug biomarkers in raw wastewater is used to back-calculate the community consumption of drugs which can reveal the trend of drug consumption (Mastroianni et al., 2017) and the effectiveness of the authorities' efforts to combat drug abuse (Li et al., 2019; Been et al., 2016a).

Conventionally, the prevalence of substance use has been estimated based on a combination of toxicology reports, crime statistics, and selfreported survey questionnaires. The conventional approaches suffer from the high cost, limited coverage, time delays for the prompt need of intervention, and biases including nonresponse bias and bias in the selection of sample population with the higher use of drugs (Keshaviah et al., 2016); therefore, potentially underestimate the actual consumption of drugs. WBE is a comprehensive, cost-effective, and nearreal-time approach that can be used as an early warning system for the prevalence of substance use or public health. However, there are several methodological uncertainties associated with the WBE: analytical uncertainties such as the selection of sampling period, sampling method, storage, sample pre-treatment, extraction, and quantification as well as the uncertainties corresponding to the parameters that are considered for back-calculation such as wastewater inflow, stability of drugs in wastewater, pharmacokinetics of the biomarker, and the population served by the wastewater treatment plant (WWTP) (Subedi, 2019; Castiglioni et al., 2013).

The stability kinetics of a drug in wastewater depends on the complexity of wastewater matrix, the residence time, temperature, and $\mathrm{pH}$ (Subedi, 2019). There is a wide-range of stability of drugs reported at varied experimental conditions such as the time period $(12 \mathrm{~h}, 24 \mathrm{~h}$, $72 \mathrm{~h}$, etc.), temperature $\left(-20^{\circ} \mathrm{C}\right.$ to $\left.20^{\circ} \mathrm{C}\right), \mathrm{pH}(1.8-7.5)$, and spiking levels of drugs (60-1000 ng/L) (Table S1) (van Nuijs et al., 2012; Baker and Kasprzyk-Hordern, 2011). Similarly, the pharmacokinetics depends on the routes of drug administration, habits of consumption, dose amount, duration of drug administration, and individuals' metabolism (Table S2) (Khan and Nicell, 2011). For instance, the estimated national prevalence of cocaine consumption based on an average rate of excretion was underestimated by $29 \%$ when considering nasal insufflation and by $182 \%$ when considering smoking as a primary mode of consumption compared to an estimate based on the constructed excretion profile of cocaine incorporating all potential routes of administration (nasal, insufflation, smoking, injection, and oral ingestion).
The conventional population estimates such as a round-figure population provided by the WWTP personnel and a census-based estimate does not account for the population dynamics such as population growth, day-specific variability, day-night variability, and residents' use of septic systems or straight-piping (Subedi, 2019). Therefore, de jure population introduces one of the greatest uncertainties for WBE estimation and consequently under- or overestimate the actual consumption (Been et al., 2014). The population dynamicity within WWTP catchment has been typically estimated based on the hydrochemical parameters (van Nuijs et al., 2011; Zheng et al., 2019), Bayesian Inference model incorporating the mass loads of chemical marker in census day (O'Brien et al., 2014), endogenous or exogenous biomarkers such as creatinine and 5-hydroxyindoleacetic acid (Brewer et al., 2012), and geographical and time reference mobile call information (Thomas et al. (2017)). Ammonia, a product of hydrolysis of urea, is a relatively more selective human-derived biomarker in wastewater - used to determine a near-accurate population in WWTP catchments and examine the diurnal variation in the prevalence of substance abuse in Switzerland (Been et al., 2014) as well as the trend in consumption of tobacco (Zheng et al., 2017) and methamphetamine in China (Zheng et al., 2019). There are very few studies that reported a statistical range of consumption rates incorporating the associated uncertainties. For instance, Been et al. determined the consumption rates of three opioids addressing uncertainties associated with flow measurements, chemical analysis, excretion, and adsorption of target drugs onto the suspended particulates using Monte Carlo simulation (Been et al., 2016b). The computational algorithm on WBE findings provided the close-agreement to the estimated load of morphine based on prescriptions and sales data in Switzerland as well as the methamphetamine prevalence in China compared to the official report (Zheng et al., 2019). Lai et al. (2011) also propagated the individual uncertainties associated with sampling, chemical analysis, flow measurements, excretion rates, and population in the WWTP catchments (Lai et al., 2011).

Despite being considered one of the countries with the highest prevalence of substance use, there are very few WBE studies reported in the U.S. (Gushgari et al., 2018). To the authors' knowledge, this is the first study utilizing Monte Carlo simulation to incorporate the uncertainties associated with the wastewater-based epidemiological determination of the prevalence of substance use in two relatively large ( $>150,000$ population) urban and a rural ( 20,000 population) communities in the U.S. The major objectives of this study were to (i) account for the uncertainties associated with the WBE using Monte Carlo simulation, (ii) determine the prevalence of ten illicit drugs [cocaine, amphetamine, methamphetamine, heroin, morphine, methadone, 3,4methylenedioxymethamphetamine (MDMA), 3,4-methylenedioxyethylamphetamine (MDEA), 3,4-methylenedioxyamphetamine (MDA), and $\Delta^{9}$-tetrahydrocannabinol (THC)] and nineteen neuropsychiatric drugs (methylphenidate, codeine, fentanyl, oxycodone, hydrocodone, hydromorphone, buprenorphine, quetiapine, aripiprazole, lorazepam, alprazolam, diazepam, oxazepam, temazepam, carbamazepine, sertraline, fluoxetine, venlafaxine, and citalopram) in urban communities, (iii) compare the prevalence of substance uses between two adjoined urban communities and that with a rural community, and (iv) compare the WBE-derived prevalence of substance uses with the conventional estimates. Moreover, the potential of three hydrochemical markers in raw wastewater was evaluated to determine a near-real population served by the WWTP.

\section{Materials and methods}

\subsection{Sample collection and preparation}

Two WWTPs from two adjoined urban communities in eastern Kentucky were sampled for seven consecutive days during a typical week in late summer of 2018. Twenty-four-hour composite samples of raw wastewater (one aliquot every $15 \mathrm{~min}$ ) were collected using a time- 
proportional autosampler and maintained at $4{ }^{\circ} \mathrm{C}$ during the collection period. According to the WWTP facility operators, $\mathrm{WWTP}_{\mathrm{A}}$ serves a population of $\sim 190,000$ people ( $60 \%$ of the city) and treats an average of 27.2 million gallons per day (MGD) of sewage from industrial and metropolitan areas. WWTP ${ }_{\mathrm{B}}$ serves a population of $\sim 150,000$ people and treats an average of $21 \mathrm{MGD}$ of sewage from more suburban areas. All collected samples were transported on ice to the laboratory and extracted within six hours of collection.

The detailed sample preparation procedures are described elsewhere (Foppe et al., 2018; Skees et al., 2018). Briefly, the collected samples were allowed to equilibrate to room temperature, thoroughly mixed, centrifuged $100 \mathrm{~mL}$ of wastewater at $4500 \mathrm{rpm}$ for $5 \mathrm{~min}$, and vacuum filtrated using glass fiber filter paper $(1.2 \mu \mathrm{m}, 4.25 \mathrm{~cm}$ diameter) to separate suspended particulate matter (SPM). Filtered samples were spiked with internal standards mixture (containing 50-150 ng of each analyte) and extracted using Oasis ${ }^{\circledR}$ hydrophilic-lipophilic balance (HLB) solid phase extraction (SPE) cartridges. Cartridges were conditioned with $3 \mathrm{~mL}$ of methanol followed by $3 \mathrm{~mL}$ of ultrapure water prior extraction. The spiked samples were passed through SPE cartridges at a flow rate of $\sim 1 \mathrm{~mL} / \mathrm{min}$, catridges were dried under vacuum for $\sim 5 \mathrm{~min}$, and stored at $-20^{\circ} \mathrm{C}$ for a week until elution. Cartridges were allowed to reach ambient temperature and then eluted with $4 \mathrm{~mL}$ of methanol followed by $3 \mathrm{~mL}$ of $5 \%$ ammonia in methanol. The extracts were combined and concentrated to $250 \mu \mathrm{L}$ under a gentle stream of nitrogen at ambient temperature. The concentrate was transferred quantitatively to an amber silanized HPLC vial and the final volume was adjusted to $\sim 1 \mathrm{~mL}$ with methanol. SPM was freeze-dried for $\sim 6 \mathrm{~h}$, allowed to reach room temperature, spiked with the internal standard mixture, vortexed with $6 \mathrm{~mL}$ of methanol, and ultra-sonicated for $30 \mathrm{~min}$. SPM samples were then centrifuged at $4500 \mathrm{rpm}$ for $5 \mathrm{~min}$ and the supernatant liquid was collected. The SPM samples were re-extracted with another $6 \mathrm{~mL}$ of methanol and the extracts were combined. Extracted samples were then concentrated to ${ }^{\sim} 250 \mu \mathrm{L}$ under a gentle stream of nitrogen, quantitatively (several methanol rinses) transferred to amber silanized HPLC vials, and adjusted the final volume to $\sim 1 \mathrm{~mL}$ with methanol. All prepared samples were subjected to ultra-performance liquid chromatography (UPLC) tandem mass spectrometry (MS/ MS) analysis of target drug residues (Supporting Info).

\subsection{Isotope dilution liquid chromatography-tandem mass spectrometry}

The prepared samples were analyzed for target drug residues using UPLC (Agilent 1290 Infinity II LC System) coupled with Triple Quadrupole mass spectrometer (Agilent 6460) (Santa Clara, CA). The gradient flow of HPLC grade methanol and $0.1 \%$ aqueous solution of formic acid were used to separate analytes using a Force Biphenyl chromatographic column $(100 \mathrm{~mm} \times 2.1 \mathrm{~mm}$ i.d. $\times 1.8 \mu \mathrm{m}$ particle size). Target analyte's peak identification was based on the relative retention time ( $\pm 0.05 \mathrm{~min}$ ) to their standard solution, two parent-todaughter ions transitions, and the ratio of the abundance of quantitative to qualitative ions ( $\pm 20 \%$ ) (Skees et al., 2018). The isotopic dilution mass spectrometry method was applied where a known quantity of deuterated isotopes of each target analyte (internal standard) is spiked directly into the sample before sample preparation and analytes are quantified based on the relative response factors of isotopic-labeled internal standard and the corresponding analyte. This method allows for accurate quantification by correcting for the loss of analytes during the sample preparation and instrumental analysis process. The five-toten-point calibration curves of each target analyte were prepared by plotting the concentration-dependent response factor against the response dependent concentration factor. The linear or quadratic (four analytes) regression coefficients determined using Agilent MassHunter Workstation for the Quantitative Analysis were $r^{2} \geq 0.99$ for all analytes. The details of quality assurance and quality controls are provided in supporting information.
Table 1

Population in WWTP catchments.

\begin{tabular}{llll}
\hline Communities & $\begin{array}{l}\text { Census } \\
\text { Population* }\end{array}$ & $\mathrm{NH}_{4}-\mathrm{N}(\mathrm{mg} / \mathrm{d})^{* * *}$ & $\begin{array}{l}\mathrm{NH}_{4}-\mathrm{N}-\text { based } \\
\text { Population** }\end{array}$ \\
\hline Urban A & 190,000 & $13.1 \pm 1.2$ & $189,335 \pm 12,757$ \\
Urban B & 150,000 & $14.1 \pm 1.6$ & $157,796 \pm 20,187$ \\
Rural & 20,000 & $9.82 \pm 0.34$ & $21,835 \pm 1742$ \\
\hline
\end{tabular}

*provided by the WWTP operators; **average \pm standard error.

\subsection{Estimation of population}

Three candidate hydrochemical markers: ammoniacal nitrogen $\left(\mathrm{NH}_{4}-\mathrm{N}\right)$, total phosphorous, and biological oxygen demand (BOD) are assessed for their suitability to estimate the size of the population (Eq. (1)).

$P_{i, j}=\frac{C_{B_{i}} \times F_{j}}{R_{B_{i}}} i=1,2,3$ and $j=1,21 \ldots \ldots .7$

where $C_{B_{i}}$ is the concentration of a hydrochemical marker $(\mathrm{mg} / \mathrm{L})$ (Table S3), $F_{j}$ is the wastewater inflow (L/d) for the $j^{\text {th }}$ day, and $R_{B_{i}}$ is an average per capita daily production of the $i^{\text {th }}$ hydrochemical marker ( $\mathrm{NH}_{4}-\mathrm{N}$ : $6900 \mathrm{mg} / \mathrm{d}$ (Been et al., 2014); phosphorous: $1700 \mathrm{mg} / \mathrm{d}$ (van Nuijs et al., 2011); and BOD: $5900 \mathrm{mg} / \mathrm{d}$ (van Nuijs et al., 2011)). The estimated population using these markers varied considerably during seven days of the sampling period (Fig. S1). Overall, $\mathrm{NH}_{4}-\mathrm{N}$ based population (Table 1) was found more reliable (RSD: $18 \%, \mathrm{n}=7$ ) compared to the total phosphorus (RSD: $21 \%, \mathrm{n}=7$ ) and BOD-based populations (RSD: $36 \%, n=7$ ) in urban A; therefore, it was considered to estimate the prevalence of substance uses in this study. Though more accurate, $\mathrm{NH}_{4}-\mathrm{N}$ based population still subject to have uncertainty and is accounted through uncertainty analysis discussed in Section 2.5.

\subsection{Estimation of the consumption rate of drugs}

The mass load and the consumption rate of target drugs were determined using Eqs. (2) and (3) similar as described elsewhere (Foppe et al., 2018; Subedi and Kannan, 2014; Skees et al., 2018).

$$
\begin{aligned}
& \text { Mass load }=\left(C \pm S_{C}\right) \times\left(F \pm S_{F}\right) \times \frac{100}{\left[100+\left(\text { Stability }+S_{\text {stability }}\right)\right]} \\
& \times \frac{1}{1 \times 10^{6}} \\
& \text { Consumption/1000 people }= {\left[\text { Mass Load } \pm S_{M L}\right] \times\left[\frac{100}{\left(E x \pm S_{E x}\right.}\right] } \\
& \times {\left[\frac{M W_{\text {par }}}{M W_{\text {met }}}\right] \times\left[\frac{1000}{\left(P o p \pm S_{P o p}\right)}\right] }
\end{aligned}
$$

where mass load is the amount of individual illicit drugs introduced into WWTP $(\mathrm{mg} / \mathrm{d}), C$ is the total nanograms of analytes in $1 \mathrm{~L}$ of wastewater influent and SPM combined (ng/L), $F$ is the daily flow rate of wastewater influent $(\mathrm{L} / \mathrm{d})$ over a $24 \mathrm{~h}$ period, and stability is a measure of stability change (\%) of analyte in wastewater up to $12 \mathrm{~h}$ (Table S1). $S_{C}$ and $S_{F}$ are the standard errors associated with the estimated sample mean concentration of drugs and the wastewater inflow, respectively. Similarly, consumption rate of drugs was determined as the milligrams of drugs per 1000 people, $E_{\mathrm{x}}$ is the percentage excretion rates (Table S2), $M W_{\text {par }}$ is the molar mass of parent drug, $M W_{\text {met }}$ is the molar mass of metabolite, Pop is an estimated population size based on $\mathrm{NH}_{4}-\mathrm{N}$ load in the raw wastewater. The $S_{M L}, S_{E x}, S_{P o p}$ are the standard errors associated with the estimated average mass load, reported excretion rates, and the estimated population, respectively. The mass loadings and the cosnumption rates of cocaine, heroin, methadone, and THC were determined based on the residual levels of their stable metabolites in the wastewater: benzoylecgonine, 6-acetyl morphine, EDDP, and THCA, respectively. The mass loading and the consumption rate of all other 
drugs were determined utilizing the residual concentrations of their unchanged parent drugs in wastewater.

\subsection{Uncertainty treatment using Monte Carlo simulation}

All input variables used in the Eqs. (2) and (3) are measured with the error or reported with inherent uncertainty. Consequently, estimates from back-calculations subject to various uncertainties associated with different variables or different steps involved or both. Additionally, the formula used for determining mass loading and the consumption rates are not a linear function of the individual parameters used, and thus the errors associated with the estimates are not trackable analytically. As the calculation became more complex, a more general approach is needed to account uncertainties (Jones et al., 2014).

In this study, we implemented a Monte Carlo (MC) simulation to account multiple sources of uncertainty associated with the individual parameters involved in WBE estimations. The MC is a computing algorithm to draw repeated random sampling from a given probability distribution and offers powerful tools to model propagation of the uncertainties. For implementing MC methods, all parameters involved in the back-calculation (Eqs. (2) and (3)) are assumed to have a normal distribution with an estimated value of the parameter as the mean and associated standard error of the estimate to the standard deviation of the distribution (see tables S1, S2, S3, and S4 for the sample mean and associated standard error). For drugs with only one reported value for stability and excretion rate, the same value was used in all MC samples while performing back calculations. Individual values of the input parameter are then randomly generated from the assumed normal distribution, and the simulated values of the input parameters are later used in the back calculations. The use of these repeated random samples of input parameter in the back calculations generate simulated values for the variable of interest such as mass loading and the consumption rates. The values obtained from the back calculations are used to find the point estimates and confidence interval for the parameter such as average mass loading and average per capita consumption rates. Additionally, for comparing prevalence of the substance use in three communities, mean difference (MD), as well as $95 \%$ confidence interval for MDs, are constructed. A 95\% confidence interval for a true parameter is interpreted as a range in which there is a $95 \%$ probability that the true parameter lies. Two communities are considered significantly different at the $5 \%$ significance level if a $95 \%$ confidence interval (CI) for the MD does not contain zero.

\section{Results and discussion}

Seven residual illicit drugs and sixteen prescribed psychoactive drugs were detected in $100 \%$ of the collected wastewater samples from two WWTP in urban communities (Table S4). Benzoylecgonine, a cocaine metabolite, dominates the illicit drug profile while antidepressants dominate the prescribe psychoactive drug levels in wastewater.

\subsection{Drug consumption in two adjoined urban communities}

Urban communities include one of the most educated ( $>43.6 \%$ of people have at least college education) and lively ( $40 \%$ population adults) cities in the country. The urban community A (urban A hereinafter) in Eastern Kentucky comprises the central business district, downtown, industrial, and the University area. Similarly, the adjoined community B (urban B hereinafter) is a fast-growing suburban area.

Table 2 presents the mean consumption rate, MD of the consumption rates and associated 95\% CI. The mean per-capita consumption rate of cocaine in the central business district (urban A: $3830 \mathrm{mg} / \mathrm{d}$ / 1000 people) was found significantly higher (MD: $1980 \mathrm{mg} / \mathrm{d} / 1000$ people) than in urban $B(1850 \mathrm{mg} / \mathrm{d} / 1000$ people $)$ while the consumption rate of other stimulants such as amphetamine, methamphetamine, and methylphenidate was statistically equivalent. (Table 2 and Fig. 1). Accounting several individual uncertainties in WBE estimation, Lai et al. (2011) also reported several hundred milligrams of daily consumption of cocaine, methamphetamine, and MDMA per 1000 people daily in a vibrant urban community (population 300,000-350,000) in South East Queensland, Australia (Lai et al., 2011).

Similarly, among nine potentially abused opioids/narcotics, the hydromorphone consumption in urban A $(67 \mathrm{mg} / \mathrm{d} / 1000$ people) was found significantly higher (MD: $27 \mathrm{mg} / \mathrm{d} / 1000$ people) than in urban $\mathrm{B}$. The buprenorphine was consumed most in both communities ( $1600 \mathrm{mg} / \mathrm{d} / 1000$ people) followed by oxycodone $(\sim 500 \mathrm{mg} / \mathrm{d} / 1000$ people) among the prescribed narcotics. In fact, the prescription doses of buprenorphine and oxycodone in these communities were the highest in Kentucky (Kentucky All Schedule Prescription Electronic Reporting, 2018).

Recently, fentanyl overdose death rates $(52 \%$ of total overdose deaths) surpassed the heroin-related as well as the prescription opioidrelated deaths in Kentucky (Kentucky Injury Prevention and Research Center, 2019). The fentanyl and heroin-related overdose deaths in urban A and B were among the highest in the state (Kentucky Office of Drug Control Policy, 2017). In this study, the prevalence of fentanyl and heroin abuse were similar in both urban communities. Although the prevalence of cocaine abuse and hydromorphone use was significantly higher in the central business district, the consumption rate of prescribed psychoactive drugs such as carbamazepine [1580 (MD: 835) $\mathrm{mg} / \mathrm{d} / 1000$ people] and temazepam [benzodiazepine of potential abuse, 37 (MD: 21) mg/d/1000 people] were significantly higher in urban B.

\subsection{Prevalence of drug consumption between urban and rural communities}

The median per-capita income of a rural community $(\$ 17,650)$ was 1.8 times lower than in urban A and B (United States Census Bureau, 2019). The estimated average population of rural, urban $A$, and urban $B$ communities were $21,835 \pm 1742, \quad 189,335 \pm 12,757$, and $157,796 \pm 20,187$, respectively, based on ammoniacal nitrogen load in raw wastewater for a week (Table 1). Our research group reported the consumption rates of several drugs from a rural community in western Kentucky (Skees et al., 2018). The reported consumption rate of drugs in a rural community in western Kentucky, after incorporating the potential uncertainties in WB-epidemiological estimation, is hereby compared to that found at two urban communities.

The prevalence of cocaine consumption was significantly higher in urban communities compared to a rural community whereas the consumption rates of amphetamine and methylphenidate are significantly higher in the rural community (Table 2, Fig. 2). One-day equivalent dose of cocaine costs approximately $\$ 110$ while the amphetamine/ methamphetamine cost $\$ 40$ per day (Postigo et al., 2008; Department of Consumer Protection, 2019; RehabCenter.net, 2019). In Australia, a WBE study that involved WWTPs serving $40 \%$ of the continent's population found that the cocaine consumption in urban areas was higher than rural areas by up to two orders of magnitude (Lai et al., 2016).

In contrast to the present study, the majority of recent WBE studies have found that methamphetamine consumption is similar in both urban and rural areas with no clear geographical pattern (Lai et al., 2016; Du et al., 2015). Thomas et al. found an inverse relationship between cocaine and methamphetamine prevalence in a study comparing 19 European cities, in which Finland, Norway, and the Czech Republic had low rates of cocaine consumption but the highest rates of methamphetamine use (Thomas et al., 2012). In the Midwest U.S., particularly western Kentucky, the clandestine methamphetamine laboratories are historically more prevalent (National Drug Intelligence Center, 2019; United States Drug Enforcement Agency, 2019). Therefore, the relative lower cost and accessibility of methamphetamine/ amphetamine can have resulted in a higher prevalence in the rural 
Table 2

Consumption rate of drugs in urban A, urban B, and a rural community in Kentucky, U.S. The values in parenthesis represent the $95 \%$ confidence interval.

\begin{tabular}{|c|c|c|c|c|c|c|}
\hline \multirow[t]{2}{*}{ Analytes } & \multicolumn{3}{|c|}{$\begin{array}{l}\text { Consumption Rate (mg/d/1000 people) } \\
\text { (95\% Confidence Interval) }\end{array}$} & \multicolumn{3}{|c|}{$\begin{array}{l}\text { Mean difference } \\
\text { (95\% Confidence Interval) }\end{array}$} \\
\hline & Urban A & Urban B & Rural & Urban A - Urban B & Urban A - Rural & Urban B - Rural \\
\hline \multicolumn{7}{|l|}{$\underline{\text { Stimulants }}$} \\
\hline Cocaine (CCN)* & $3830(2850,5060)$ & $1850(1170,2780)$ & $864(471,1440)$ & $1980(785,3250)$ & $2960(1920,4200)$ & $984(149,1970)$ \\
\hline Cocaine $* *$ & $2790(2040,3710)$ & $1180(748,1760)$ & $363(199,603)$ & $1610(698,2600)$ & $2430(1650,3350)$ & $816(332,1430)$ \\
\hline Amphetamine (AMP) & $400(279,556)$ & $344(208,535)$ & $738(446,1100)$ & $344(208,535)$ & $-338(-677,-43)$ & $-393(-748,-78)$ \\
\hline Methamphetamine (MAPT) & $1030(721,1400)$ & $1160(694,1790)$ & $1660(985,2460)$ & $1160(694,1790)$ & $-629(-1430,81)$ & $-276(-1260,581)$ \\
\hline Methylphenidate (MPD) & $284(185,398)$ & $290(198,415)$ & $605(372,885)$ & $-6(-163,142)$ & $-321(-616,-62)$ & $-315(-611,-50)$ \\
\hline \multicolumn{7}{|l|}{ Opioids/Narcotics } \\
\hline Heroin* (HER) & $1620(961,2700)$ & $1810(600,3610)$ & $\mathrm{n} / \mathrm{a}$ & $-187(-1730,1130)$ & $\mathrm{n} / \mathrm{a}$ & $\mathrm{n} / \mathrm{a}$ \\
\hline Morphine (MPH) & $312(208,452)$ & $229(140,357)$ & $99(54,167)$ & $83(-46,214)$ & $213(107,345)$ & $130(34,254)$ \\
\hline Methadone* (MTD) & $106(65,178)$ & $92(53,160)$ & $1410(708,2600)$ & $14(-31,60)$ & $\begin{array}{l}-1300(-2450, \\
-620)\end{array}$ & $-1317(-2490,-635)$ \\
\hline Methadone $* *$ & $449(289,716)$ & $428(253,716)$ & NA & $21(-178,204)$ & NA & NA \\
\hline Codeine (CDN) & $50(31,86)$ & $52(28,96)$ & $192(87,388)$ & $-2(-32,21)$ & $-142(-320,-44)$ & $-140(-319,-42)$ \\
\hline Fentanyl (FNT) & $169(85,391)$ & $134(54,324)$ & $31(13,72)$ & $35(-57,150)$ & $138(66,327)$ & $103(32,267)$ \\
\hline Oxycodone (OCD) & $566(272,1060)$ & $459(232,866)$ & $465(217,919)$ & $107(-230,474)$ & $101(-281,488)$ & $-6(-367,325)$ \\
\hline Hydrocodone (HCD) & $166(126,213)$ & $134(93,189)$ & $507(289,820)$ & $33(-35,95)$ & $-341(-657,-118)$ & $-373(-689,-149)$ \\
\hline Hydromorphone (HMP) & $67(51,87)$ & $40(28,56)$ & $142(82,226)$ & $27(4,51)$ & $-75(-161,-11)$ & $-102(-187,-40)$ \\
\hline Buprenorphine (BPN) & $1700(1220,2260)$ & $1480(975,2150)$ & $3150(1800,5030)$ & $219(-568,955)$ & $-1450(-3370,-2)$ & $-1670(-3600,-176)$ \\
\hline \multicolumn{7}{|l|}{ Hallucinogens } \\
\hline$\overline{M D M A}$ & $28(19,40)$ & $21(11,36)$ & $\mathrm{n} / \mathrm{a}$ & $7(-10,21)$ & $\mathrm{n} / \mathrm{a}$ & $\mathrm{n} / \mathrm{a}$ \\
\hline MDEA & $25^{*}$ & $<\mathrm{LOQ}$ & $\mathrm{n} / \mathrm{a}$ & $\mathrm{n} / \mathrm{a}$ & $\mathrm{n} / \mathrm{a}$ & $\mathrm{n} / \mathrm{a}$ \\
\hline MDA & $6(5,8)$ & $<\mathrm{LOQ}$ & $\mathrm{n} / \mathrm{a}$ & $\mathrm{n} / \mathrm{a}$ & $\mathrm{n} / \mathrm{a}$ & $\mathrm{n} / \mathrm{a}$ \\
\hline THC $^{*}$ & $\begin{array}{l}88100(54000- \\
134000)\end{array}$ & $\begin{array}{l}78700(48500- \\
122000)\end{array}$ & $\mathrm{n} / \mathrm{a}$ & $9400(-35500-53200)$ & $\mathrm{n} / \mathrm{a}$ & $\mathrm{n} / \mathrm{a}$ \\
\hline \multicolumn{7}{|l|}{ Antischizophrenics } \\
\hline$\overline{\text { Quetiapine (QTP) }}$ & $31(26,36)$ & $33(21,48)$ & $31(18,49)$ & $-2(-21,14)$ & $0(-22,17)$ & $2(-22,18)$ \\
\hline \multicolumn{7}{|c|}{ Sedatives-Hypnotics-Anxiolytics } \\
\hline Lorazepam (LZP) & $8(5,10)$ & $12(8,17)$ & $26(16,37)$ & $-4(-11,1)$ & $-14(-29,-4)$ & $-14(-27,-4)$ \\
\hline Alprazolam (APZ) & $66(53,81)$ & $68(49,94)$ & $30(17,50)$ & $-2(-31,23)$ & $36(13,56)$ & $38(10,68)$ \\
\hline Diazepam (DZP) & $3(2,5)$ & $<\mathrm{LOQ}$ & $4(2,4)$ & $\mathrm{n} / \mathrm{a}$ & $-1(-3,2)$ & $\mathrm{n} / \mathrm{a}$ \\
\hline Oxazepam (OXZ) & $3(2,5)$ & $4(2,7)$ & $40(23,63)$ & $-1(-4,2)$ & $-37(-60,-20)$ & $-36(-59,-19)$ \\
\hline Temazepam (TMZ) & $16(10,23)$ & $37(24,55)$ & $83(48,132)$ & $-21(-40,-6)$ & $-67(-116,-32)$ & $-46(-96,-7)$ \\
\hline Carbamazepine (CRB) & $749(567,959)$ & $1580(1000,2350)$ & $615(347,1000)$ & $-835(-1620,-217)$ & $134(-289,479)$ & $969(279,1780)$ \\
\hline \multicolumn{7}{|l|}{ Antidepressants } \\
\hline Sertraline (SRT) & $11700(7960,15100)$ & $14300(9020,21400)$ & $4030(2180,6730)$ & $-2700(-11600,4610)$ & $7620(2550,12,150)$ & $10300(5230,14000)$ \\
\hline Fluoxetine (FLX) & $581(459,724)$ & $787(547,1110)$ & $210(115,349)$ & $-206(-547,73)$ & $371(192,545)$ & $577(304,923)$ \\
\hline Venlafaxine (VNF) & $4750(3470,6240)$ & $6230(4200,8960)$ & $5450(3150,8720)$ & $-1480(-4400,1010)$ & $-705(-4160,2020)$ & $775(-3060,4350)$ \\
\hline Citalopram (CTP) & $916(536,1600)$ & $1080(599,1940)$ & $1160(565,2250)$ & $-159(-720,285)$ & $-248(-1060,323)$ & $-89(-909,603)$ \\
\hline
\end{tabular}

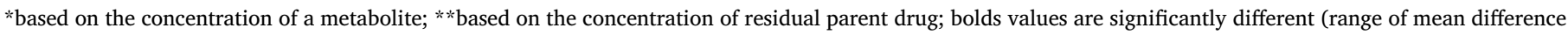
did not include zero); < LOQ: below the limit of quantitation, n/a: non-applicable.

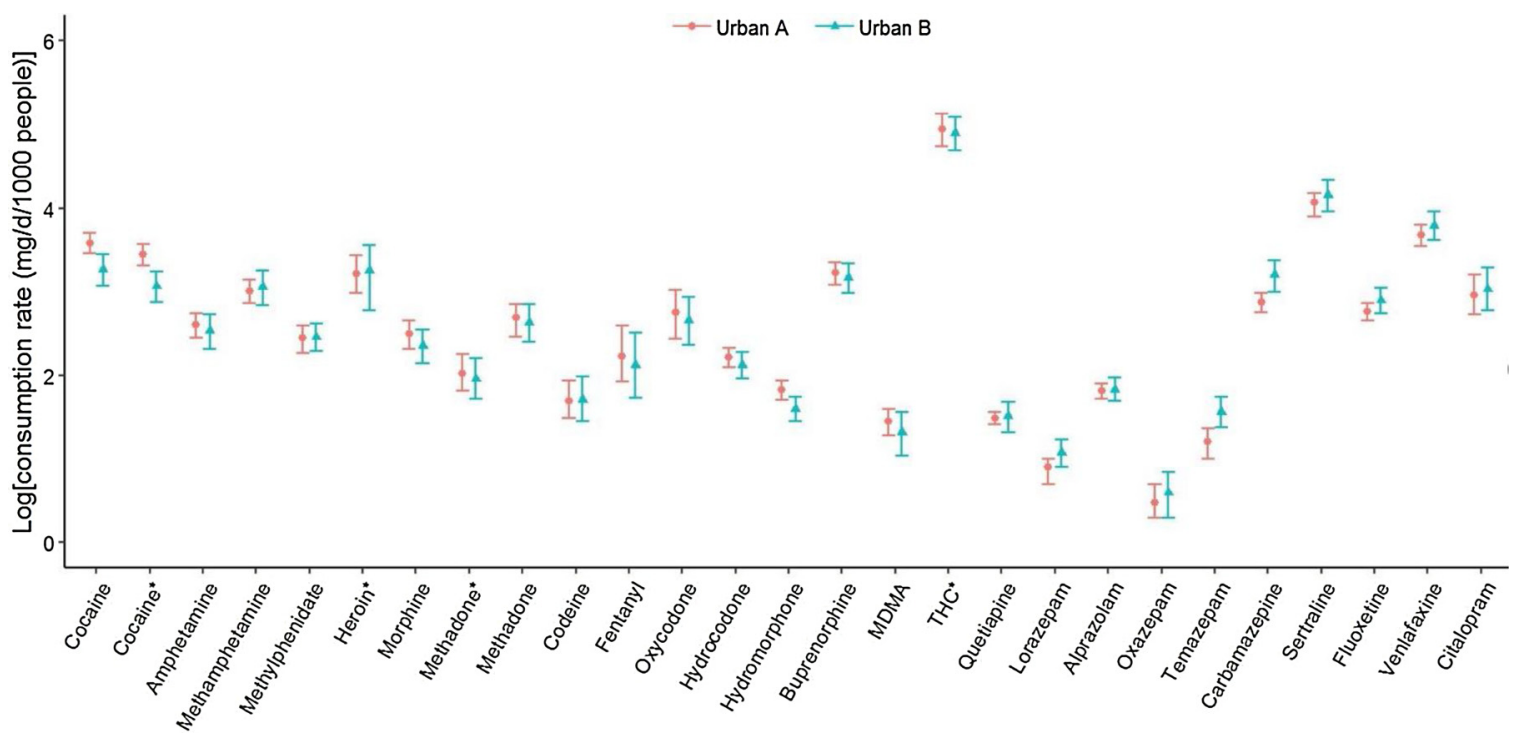

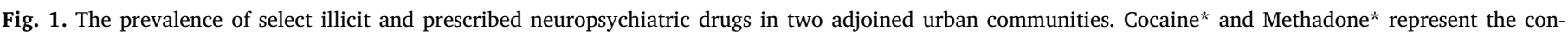

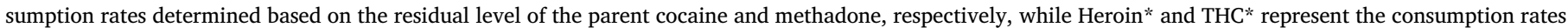

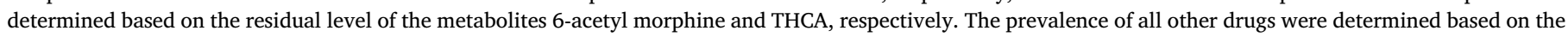
residual level of their parent drugs. 


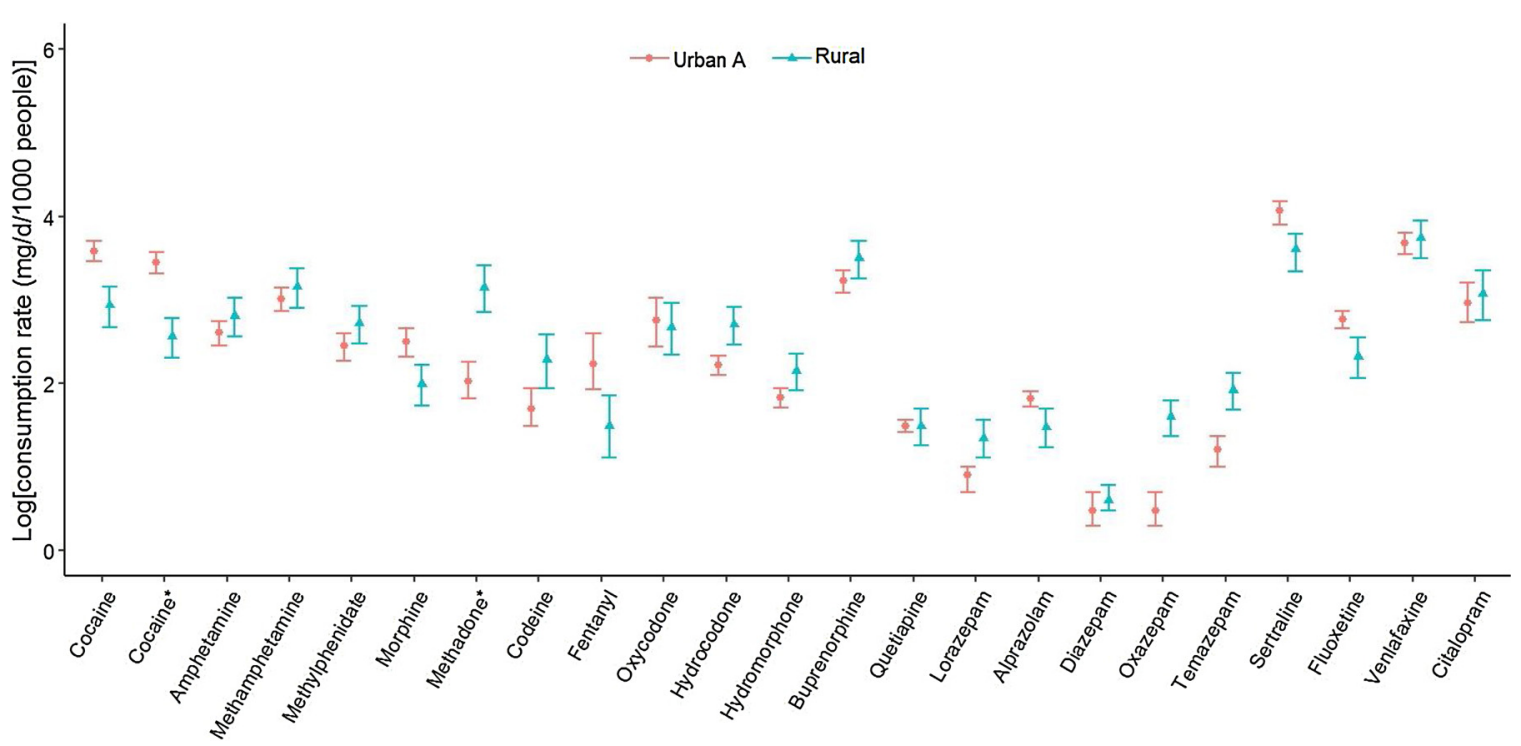

Fig. 2. The prevalence of select illicit and prescribed neuropsychiatric drugs in urban A and a rural community. Cocaine* and Methadone* represent the consumption rates determined based on the residual level of the parent cocaine and methadone, respectively, while Heroin* and THC* represent the consumption rates determined based on the residual level of the metabolites 6-acetyl morphine and THCA, respectively. The prevalence of all other drugs were determined based on the residual level of their parent drugs.

community in western Kentucky. Amphetamine and methylphenidate, schedule II stimulants, are the active ingredients of prescribed drugs Adderall $^{\circledast}$, Concerta ${ }^{\circledR}$, Ritalin ${ }^{\circledR}$, etc. As the prescription rate of amphetamine and methylphenidate drugs is higher in urban A and B communities (Jones et al., 2014); a significantly higher consumption rate of these drugs in the western rural community suggests additional sources of amphetamine and methylphenidate. The overall consumption of schedule II stimulants in Kentucky is predominant ( $>2$ folds higher) among individuals age $<34$ compared to the individuals $>34$ (Jones et al., 2014), and $\sim 10 \%$ of the total population are current college students in urban A and B communities while $\sim 40 \%$ of the total population are current college students in the rural community. Therefore, the difference in population profile in urban and rural communities can also have contributed to a differential consumption rate of amphetamine and methylphenidate.

The opioid overdose resulting $>130$ fatalities every day in the U.S., and the opioid-related overdose deaths in Kentucky is one of the highest in the country (National Institute on Drug Abuse, 2019). In this study, the prevalence of fentanyl and morphine consumptions in urban communities were significantly higher than in a rural community while the prevalence of prescribed opioids such as codeine, hydrocodone, hydromorphone, and buprenorphine consumptions was significantly higher in the rural community (Table 2, Fig. 2). This suggests that the overall prevalence of opioid consumption in rural communities can be equally or higher than in urban communities.

Among prescribed psychoactive drugs, alprazolam was found significantly higher in urban communities while temazepam, oxazepam, and lorazepam were found significantly higher in the rural community. The consumption rate of carbamazepine in an urban B was significantly higher [1584 (MD: 969) mg/d/1000 people] than in a rural community. Similarly, the consumption of sertraline, a prescribed antidepressant, in urban communities was $2-3$ folds higher than in the rural community.

3.3. WBE-derived vs conventional estimates of the prevalence of substance uses

The statewide controlled substance prescription monitoring system, Kentucky All Schedule Prescription Electronic Reporting (KASPER), reports a threshold analysis report based on the conventional estimate of select schedule II through $\mathrm{V}$ controlled substance -dispensing in Kentucky (Jones et al., 2014). Based on the reported prescription doses per 1000 people in all 120 counties in the state including the study areas and the typical daily doses (www.rxlist.com), the total amount of prescribed drugs (milligrams/day) were determined and compared with the WBE estimates in this study (Fig. 3). The population of urban communities in this study represents $\sim 90 \%$ of the total population in a county while the population of a rural community represents approximately two-third of the total population in a county.

The prevalence of alprazolam and oxycodone in urban communities was $\sim 3$ folds higher than the reported prescriptions-based KASPER estimations (Fig. 3); however, KASPER's estimations in a rural community are within $95 \%$ confidence interval of WBE estimation. It suggests the potential abuse of alprazolam and oxycodone in urban communities. Similarly, buprenorphine is $2-3$ orders of magnitude higher prevalent in urban and rural communities compared to KASPER's estimation suggests the potential abuse of buprenorphine in both communities. Kentucky Injury Prevention and Research Center (KIPRC) issues the county profiles on drug-related inpatient hospitalizations and emergency department visits in Kentucky (Kentucky All Schedule Prescription Electronic Reporting, 2018). Based on KIPRC's report in 2018, the drug-related impatient hospitalization and emergency department visits by the dependent and nondependent abusers per 1000 people in urban and rural counties were calculated. The total hospital visits by the hypnotic-sedative-anxiolytic abusers in urban communities A and B $(0.87 / 1000$ people) were 2 folds higher than in a rural community, which is a very close agreement to WBE estimations for alprazolam in this study (Fig. 3). Similarly, hospital visits by the cocaine abuser's in urban communities were an order of magnitude higher than in a rural community which is also supported by the significantly higher consumption rate of cocaine in urban communities in this study. However, KIPRC estimation of amphetamine abusers in both communities are similar ( 3 per 1000 people) despite a significantly higher consumption rate of amphetamine in the rural community was found in this study.

\subsection{Need for the evidence-based prevalence of substance uses}

As it has been demonstrated herein and several other studies, the conventional approaches typically underestimate the actual prevalence 


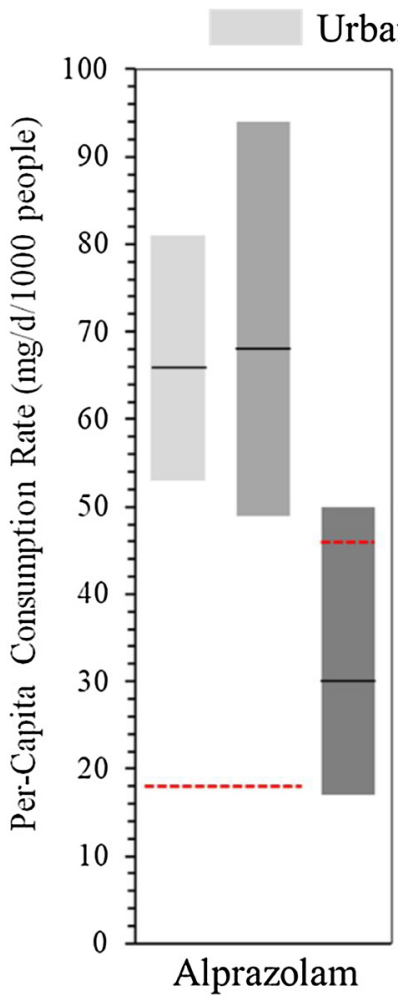

\section{Urban A}

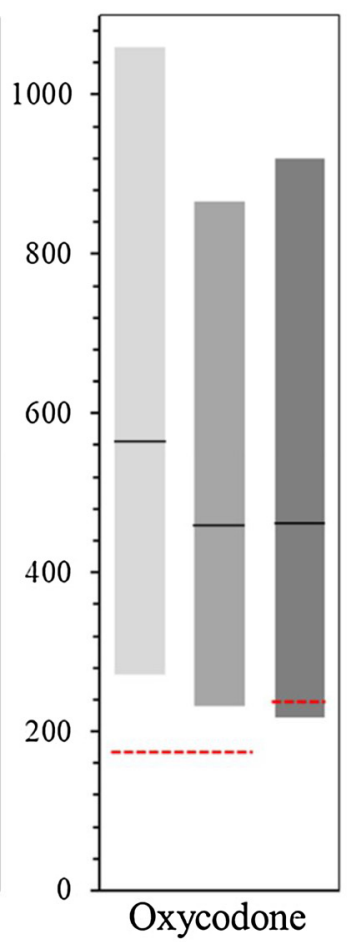

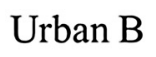

5000

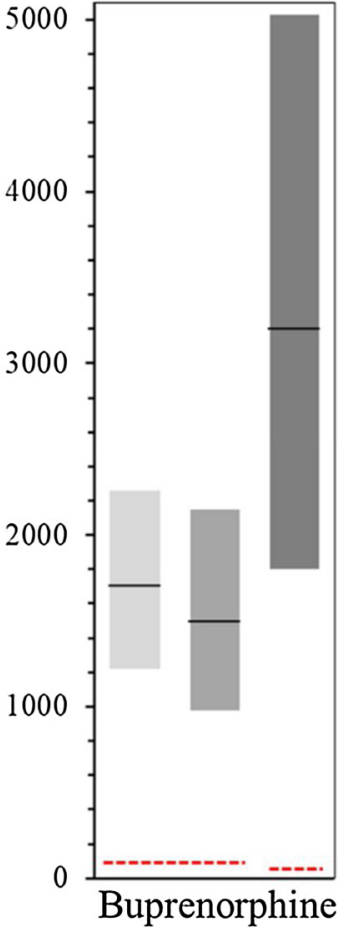

Fig. 3. Comparison between the KASPER's conventional estimation and the WBE estimation of select substances of potential abuse. The bars represent a $95 \%$ confidence interval of the WBE-derived mean consumption rate while KASPER's estimates are marked as red dotted lines. (For interpretation of the references to colour in this figure legend, the reader is referred to the web version of this article). of substances use in communities. The European Monitoring Center for Drugs and Drug Addiction (EMCDDA) established a cooperation with a group of wastewater-based epidemiologists (Sewage Analysis Core Group in Europe: SCORE) and monitoring wastewater currently from 70 European cities and complement with the WBE findings to combat drug abuse problems (Sewage Analysis Core Group in Europe, 2018). EMCDDA confirmed the overall recent surge in cocaine market in European countries based on the targeted "trendspotter" study findings such as elevated cocaine-related hospital admissions, deaths, and the WBE findings (European Monitoring Center for Drugs and Drug Addiction, 2019). Based on WBE findings, the Australian Criminal Intelligence Commission recently reported that 9.6 tons of methamphetamine, 4 tons of cocaine, 1.1 tons of MDMA and $700 \mathrm{~kg}$ of heroin were consumed within 12 months accounting $\$ 9.3$ billion (Australian Criminal Intelligence Commission (ACIC), 2019). Despite being considered one of the countries with the highest prevalence of substance use, WBE researchers in the U.S. have encountered a number of hurdles such as limited funding, access to the wastewater samples, so-called "privacy" concerns, and a lack of public health authorities' awareness on applications of WBE findings (Subedi and Burgard, 2019). At a time when drug use is on the rise, specifically for the opioid epidemic, a costeffective and semi-real time WBE approach for the comprehensive estimation of prevalence of substance use in rural as well as urban communities would be invaluable to establish an early warning system for public health biomarkers. Cost-effective and near-real-time WBE findings can assist public health surveillance programs.

\section{Funding source disclosure}

This study was funded by grants from the Kentucky Biomedical Research Infrastructure Network (Grant\# NIGMS - 8P20GM103436). The content is solely the responsibility of the authors and does not necessarily represent the official views of the sponsors.

\section{Declaration of Competing Interest}

The authors are not aware of any substantive or perceived competing interest concerning this work.

\section{Acknowledgments}

Authors are thankful to The Jones/Ross Research Center at the Department of Chemistry, Murray State University for providing access to the UPLC-MS/MS. Wastewater treatment plants are acknowledged for providing access to the $24 \mathrm{~h}$ composite wastewater samples.

\section{Appendix A. Supplementary data}

Supplementary data associated with this article can be found, in the online version, at https://doi.org/10.1016/j.jhazmat.2019.121306.

\section{References}

Australian Criminal Intelligence Commission (ACIC), 2019. Sixth Wastewater Report Reveals Australians Spend Over \$9.3 Billion a Year on Drugs. Available at https:// www.acic.gov.au/media-centre/media-releases-and-statements/sixth-wastewater-report-reveals-australians-spend-over-93-billion-year-drugs. Accessed on May 12th. .

Baker, D.R., Kasprzyk-Hordern, B., 2011. Critical evaluation of methodology commonly used in sample collection, storage and preparation for the analysis of pharmaceuticals and illicit drugs in surface water and wastewater by solid phase extraction and liquid chromatography-mass spectrometry. J. Chromatogr. A 1218, 8036-8059.

Been, F., Bastiaensen, M., Lai, F.Y., Libousi, K., Thomaidis, N.S., Benaglia, L., Esseiva, P., Delémont, O., van Nuijs, A.L.N., Covaci, A., 2018. Mining the chemical information on urban wastewater: monitoring human exposure to phosphorus flame retardants and plasticizers. Environ. Sci. Technol. 52, 6996-7005.

Been, F., Rossi, L., Ort, C., Rudaz, S., Delémont, O., Esseiva, P., 2014. Population normalization with ammonium in wastewater-based epidemiology: application to illicit drug monitoring. Environ. Sci. Technol. 48, 8162-8169.

Been, F., Esseiva, P., Delémont, O., 2016a. Analysis of illicit drugs in wastewater - is there an added value for law enforcement? Forensic Sci. Int. 266, 215-221.

Been, F., Bijlsma, L., Benaglia, L., Berset, J.D., Botero-Coy, A.M., Castiglioni, S., Kraus, L., Zobel, F., Schaub, M.P., Bücheli, A., Hernández, F., Delémont, O., Esseiva, P., Ort, C., 2016b. Assessing geographical differences in illicit drug consumption - a comparison of results from epidemiological and wastewater data in Germany and Switzerland. Drug Alcohol Depend. 161, 189-199.

Brewer, A.J., Ort, C., Banta-Green, C.J., Berset, J.D., Field, J.A., 2012. Normalized diurnal 
and between-day trends in illicit and legal drug loads that account for changes in population. Environ. Sci. Technol. 46, 8305-8314.

Burgard, D.A., Williams, J., Westerman, D., Rushing, R., Carpenter, R., LaRock, A., Sadetsky, J., Clarke, J., Fryhle, H., Pellman, M., Banta-Green, C.J., 2019. Using wastewater-based analysis to monitor the legalized retail sales effects on cannabis consumption. Addiction. https://doi.org/10.1111/add.14641. In Press.

Castiglioni, S., Bijlsma, L., Covaci, A., Emke, E., Hernández, F., Reid, M., Ort, C., Thomas, K.V., van Nuijs, A.L., de Voogt, P., Zuccato, E., 2013. Evaluation of uncertainties associated with the determination of community drug use through the measurement of sewage drug biomarkers. Environ. Sci. Technol. 47, 1452-1460.

Department of Consumer Protection, 2019. Amphetamine Salts (Mixed Amphetamines). Available at https://portal.ct.gov/DCP/Drug-Control-Division/Drug-Control/ Amphetamine-Salts-Mixed-Amphetamines. Accessed on May $12^{\text {th }}$.

Du, P., Zhou, Z., Huang, H., Han, S., Xu, Z., Bai, Y., Li, X., 2018. Estimating population exposure to phthalate esters in major Chinese cities through wastewater-based epidemiology. Sci. Total Environ. 643, 1602-1609.

Du, P., Li, K., Li, J., Xu, Z., Fu, X., Yang, J., Zhang, H., Li, X., 2015. Methamphetamine and ketamine use in major Chinese cities, a nationwide reconnaissance through sewagebased epidemiology. Water Res. 84, 76-84.

European Monitoring Center for Drugs and Drug Addiction, 2019. Recent Changes in Europe's Cocaine Market: Results from an EMCDDA Trendspotter Study, December 2018. Available at http://www.emcdda.europa.eu/system/files/publications/ 10225/2018-cocaine-trendspotter-rapid-communication.pdf. Accessed on May 12 th.

European Monitoring Center for Drugs and Drug Addiction (EMCDDA), 2019. Perspectives on Drugs: Wastewater Analysis and Drugs: a European Multi-city Study. Available at http://www.emcdda.europa.eu/system/files/publications/2757/ POD_Wastewater\%20analysis_update2019.pdf. Accessed on May 12th. .

Fernandez-Cassi, X., Timoneda, N., Martínez-Puchol, S., Rusiñol, M., Rodriguez-Manzano J., Figuerola, N., Bofill-Mas, S., Abril, J.F., Girones, R., 2018. Metagenomics for the study of viruses in urban sewage as a tool for public health surveillance. Sci. Total Environ. 618, 870-880.

Foppe, K.S., Hammond-Weinberger, D.R., Subedi, B., 2018. Estimation of the consumption of illicit drugs during special events in two communities in Western Kentucky, USA using sewage epidemiology. Sci. Total Environ. 633, 249-256.

González-Mariño, I., Rodil, R., Barrio, I., Cela, R., Quintana, J.B., 2017. Wastewater-based epidemiology as a new tool for estimating population exposure to phthalate plasticizers. Environ. Sci. Technol. 51, 3902-3910.

Gushgari, A.J., Driver, E.M., Steele, J.C., Halden, R.U., 2018. Tracking narcotics consumption at a Southwestern U.S. University campus by wastewater-based epidemiology. J. Hazard. Mater. 359, 437-444.

Jones, H.E., Hickman, M., Kasprzyk-Hordern, B., Welton, N.J., Baker, D.R., Ades, A.E., 2014. Illicit and pharmaceutical drug consumption estimated via wastewater analysis. Part B: placing back-calculations in a formal statistical framework. Sci. Total Environ. 487, 642-650.

Kentucky All Schedule Prescription Electronic Reporting, 2018. KASPER Quaterly Threshold Analysis Report Second Quater. . Available at https://chfs.ky.gov/ agencies/os/oig/dai/deppb/Documents/KASPER_Quarterly_Threshold_Report_2Q_ 2018.pdf. Accessed on May $12^{\text {th }}, 2019$.

Kentucky Injury Prevention and Research Center, 2019. County Profiles for Drug-related Inpatient Hospitalizations and Emergency Department Visits. Available at http:// www.mc.uky.edu/kiprc/pubs/overdose/county-profiles.html. Accessed on May 12th.

Kentucky Office of Drug Control Policy, 2017. Overdose Fatality Report. Available at https://odcp.ky.gov/Pages/Overdose-Fatality-Report.aspx. Accessed on May 12th, 2019.

Keshaviah, A., Gitlin, R., Cattell, L., Reeves, W., de Vallance, J., Thronton, C., 2016. The Potential of Wastewater Testing for Rapid Assessment of Opioid Abuse. Available at https://www.mathematica-mpr.com/. Accessed on May 12th, 2019.

Khan, U., Nicell, J.A., 2011. Refined sewer epidemiology mass balances and their application to heroin, cocaine and ecstasy. Environ. Int. 37, 1236-1252.

Lai, F.Y., Ort, C., Gartner, C., Carter, S., Prichard, J., Kirkbride, P., Bruno, R., Hall, W. Eaglesham, G., Mueller, J.F., 2011. Refining the estimation of illicit drug consumptions from wastewater analysis: co-analysis of prescription pharmaceuticals and un certainty assessment. Water Res. 45, 4437-4448.

Lai, F.Y., O’Brien, J., Bruno, R., Hall, W., Prichard, J., Kirkbride, P., Gartner, C., Thai, P., Carter, S., Lloyd, B., Burns, L., Mueller, J., 2016. Spatial variations in the consumption of illicit stimulant drugs across Australia: a nationwide application of wastewater-based epidemiology. Sci. Total Environ. 568, 810-818.

Li, X., Du, P., Zhang, W., 2019. Application of wastewater-based epidemiology in China from wastewater monitoring to drug control efforts. ACS Symposium Series In: Subedi, B., Burgard, D.A., Loganathan, B. (Eds.), Ed.), Wastewater-Based Epidemiology: Estimation of Community Consumption of Drugs and Diets. American Chemical Society, Washington, D.C, pp. 119-135. https://doi.org/10.1021/bk-20191319.ch006.

Mastroianni, N., López-García, E., Postigo, C., Barceló, D., López de Alda, M., 2017. Fiveyear monitoring of 19 illicit and legal substances of abuse at the inlet of a wastewater treatment plant in Barcelona (NE Spain) and estimation of drug consumption patterns and trends. Sci. Total Environ. 609, 916-926.

National Drug Intelligence Center, 2019. Kentucky Drug Threat Assessment. Available at https://www.justice.gov/archive/ndic/pubs1/1540/meth.htm. Accessed on May $12^{\text {th }}$.

National Institute on Drug Abuse, 2019. Opioids Summary by States. Available at https://www.drugabuse.gov/drugs-abuse/opioids/opioid-summaries-by-state. Accessed on May 12th.
O’Brien, J.W., Grant, S., Banks, A.P.W., Bruno, R., Carter, S., Choi, P.M., Covaci, A., Crosbie, N.D., Gartner, C., Hall, W., Jiang, G., Kaserzon, S., Kirkbride, K.P., Lai, F.Y., Mackie, R., Marshall, J., Ort, C., Paxman, C., Prichard, J., Thai, P., Thomas, K.V., Tscharke, B., Mueller, J.F., 2019. A National Wastewater Monitoring Program for a better understanding of public health: a case study using the Australian Census. Environ. Int. 122, 400-411.

O'Brien, J.W., Thai, P.K., Eaglesham, G., Ort, C., Scheidegger, A., Carter, S., Lai, F.Y., Mueller, J.F., 2014. A model to estimate the population contributing to the wastewater using samples collected on census day. Environ. Sci. Technol. 48, 517-525.

Postigo, C., de Ada, M.J.L., Barcelo, D., 2008. Analysis of drugs of abuse and their human metabolites in water by LC-MS ${ }^{2}$ : a non-intrusive tool for drug abuse estimation at the community level. TrAC Trends Anal. Chem. 27, 1053-1069.

Prado, T., Fumian, T.M., Miagostovich, M.P., Gaspar, A.M., 2012. Monitoring the hepatitis A virus in urban wastewater from Rio de Janeiro, Brazil. Trans. R. Soc. Trop. Med. Hyg. 106, 104-109.

RehabCenter.net, 2019. The Average Cost of Illegal Street Drugs. Available at https:// www.rehabcenter.net/the-average-cost-of-illegal-drugs-on-the-street/. Accessed on May 12th. .

Rousis, N.I., Gracia-Lor, E., Zuccato, E., Bade, R., Baz-Lomba, J.A., Castrignanò, E., Causanilles, A., Covaci, A., de Voogt, P., Hernàndez, F., Kasprzyk-Hordern, B., Kinyua, J., McCall, A.K., Plósz, B.G., Ramin, P., Ryu, Y., Thomas, K.V., van Nuijs, A., Yang, Z., Castiglioni, S., 2017. Wastewater-based epidemiology to assess panEuropean pesticide exposure. Water Res. 121, 270-279.

Sewage Analysis Core Group in Europe, 2018. Monitoring. Available at http://score-cost. eu/monitoring2018/. Accessed on May $12^{\text {th }}, 2019$.

Skees, A.J., Foppe, K.S., Loganathan, B., Subedi, B., 2018. Contamination profiles, mass loadings, and sewage epidemiology of neuropsychiatric and illicit drugs in wastewater and river waters from a community in the Midwestern United States. Sci. Total Environ. 631-632, 1457-1464.

Subedi, B., 2019. Uncertainties associated with the wastewater-based epidemiology for the estimation of rates of drug consumption. ACS Symposium Series In: Subedi, B., Burgard, D.A., Loganathan, B.G. (Eds.), Wastewater-Based Epidemiology: Estimation of Community Consumption of Drugs and Diets. American Chemical Society, Washington, D.C, pp. 79-98. https://doi.org/10.1021/bk-2019-1319.ch004.

Subedi, B., Burgard, D., 2019. Wastewater-based epidemiology as a complementary approach to the conventional survey-based approach for the estimation of community consumption of drugs. ACS Symposium Series In: Subedi, B., Burgard, D.A., Loganathan, B.G. (Eds.), Wastewater-Based Epidemiology: Estimation of Community Consumption of Drugs and Diets. American Chemical Society, Washington, D.C, pp. 3-21. https://doi.org/10.1021/bk-2019-1319.ch001.

Subedi, B., Kannan, K., 2014. Mass loading and removal of select illicit drugs in two wastewater treatment plants in New York State and estimation of illicit drug usage in communities through wastewater analysis. Environ. Sci. Technol. 48, 6661-6670.

Subedi, B., Balakrishna, K., Sinha, R.K., Yamashita, N., Balasubramanian, V.G., Kannan, K., 2015. Mass loading and removal of pharmaceuticals and personal care products, including psychoactive and illicit drugs and artificial sweeteners, in five sewage treatment plants in India. J. Environ. Chem. Eng. 3, 2882-2891.

Thomas, K.V., Amador, A., Baz-Lomba, J.A., Reid, M., 2017. Use of mobile device data to better estimate dynamic population size for wastewater-based epidemiology. Environ. Sci. Technol. 51, 11363-11370.

Thomas, K.V., Bijlsma, L., Castiglioni, S., Covaci, A., Emke, E., Grabic, R., Hernández, F., Karolak, S., Kasprzyk-Hordern, B., Lindberg, R.H., Lopez de Alda, M., Meierjohann, A., Ort, C., Pico, Y., Quintana, J.B., Reid, M., Rieckermann, J., Terzic, S., van Nuijs, A.L., de Voogt, P., 2012. Comparing illicit drug use in 19 European cities through sewage analysis. Sci. Total Environ. 432, 432-439.

U. S. Department of Health and Human Services, 2019. HHS Acting Secretary Declares Public Health Emergency to Address National Opioid Crisis. Available at https:// www.hhs.gov/about/news/2017/10/26/hhs-acting-secretary-declares-publichealth-emergency-address-national-opioid-crisis.html. Accessed on May $12^{\text {th }}$.

United Nation Office on Drugs and Crime, 2018. World Drug Report. . Available at https://www.unodc.org/wdr2018/. Accessed on May 12 $2^{\text {th }}, 2019$.

United States Census Bureau, 2019. Quick Facts. Available at https://www.census.gov/ quickfacts/fact/table/US/PST045218. Accessed on May $12^{\text {th }}$.

United States Drug Enforcement Agency, 2019. Drug Labs in the United States: National Clandestine Laboratory Register Data. Available at https://www.dea.gov/clanlab state $=$ KY\&date $=$. Accessed on May 12th.

van Nuijs, A.L., Abdellati, K., Bervoets, L., Blust, R., Jorens, P.G., Neels, H., Covaci, A., 2012. The stability of illicit drugs and metabolites in wastewater, an important issue for sewage epidemiology? J. Hazard. Mater. 239-240, 19-23.

van Nuijs, A.L., Mougel, J.F., Tarcomnicu, I., Bervoets, L., Blust, R., Jorens, P.G., Neels, H., Covaci, A., 2011. Sewage epidemiology - a real-time approach to estimate the consumption of illicit drugs in Brussels, Belgium. Environ. Int. 37, 612-621.

Venkatesan, J.C.A., Driver, E., Gushgari, A., Halden, R., 2019. Assessing the potential to monitor plant-based diet trends in communities using wastewater-based epidemiology approach. ACS Symposium Series In: Subedi, B., Burgard, D.A., Loganathan, B.G. (Eds.), Wastewater-Based Epidemiology: Estimation of Community Consumption of Drugs and Diets. American Chemical Society, Washington, D.C, pp. 187-198. https://doi.org/10.1021/bk-2019-1319.ch010.

Zheng, Q.D., Wang, Z., Liu, C.Y., Yan, J.H., Pei, W., Wang, D.G., 2019. Applying a population model based on hydrochemical parameters in wastewater-based epidemiology. Sci. Total Environ. 657, 466-475.

Zheng, Q.D., Lin, J.G., Pei, W., Guo, M.X., Wang, Z., Wang, D.G., 2017. Estimating nicotine consumption in eight cities using sewage epidemiology based on ammonia nitrogen equivalent population. Sci. Total Environ. 590-591, 226-232. 